\title{
Latent inhibition in preweanling rats
}

\author{
PHILIPP J. KRAEMER and CHRISTOPHER K. RANDALL \\ University of Kentucky, Lexington, Kentucky
}

\begin{abstract}
Two experiments describe a latent inhibition effect in preweanling rats. Subjects were trained with a light-tone compound conditioned stimulus (CS) paired with a footshock unconditioned stimulus. Experiment 1 tested 17-and 21-day-old rats and Experiment 2 tested 18-day-old rats. In each experiment, rat pups given nonreinforced preexposure to the CS expressed less conditioned fear, as indexed by a suppression in general activity during the CS, than did same-age control rats given no preexposure. The results are discussed in terms of behavioral development and the role of the functional maturity of the hippocampus in latent inhibition.
\end{abstract}

The analysis of brain-behavior relations is a critical part of psychobiological research. An area of inquiry that has benefitted significantly from this research strategy is the study of learning and memory. Both clinical and experimental investigations have been used to establish a number of important correlations between cognitive and neurological functioning (Kolb \& Whishaw, 1990; Meck, Church, \& Olton, 1984; Mishkin, Malamut, \& Bachevalier, 1984; Olton, Becker, \& Handlemann, 1979).

Developmental studies of learning and memory have also been used to establish brain-behavior relations. In many of these studies, researchers have relied on agerelated comparisons of cognitive competence, in conjunction with anatomical and neurophysiological assays, to infer the neurological basis of various cognitive processes (Amsel, 1986; Bachevalier \& Mishkin, 1984; Nadel \& Zola-Morgan, 1984).

Although studies of behavioral development offer a valuable contribution to the analysis of brain-behavior relations, it is also clear that all inferences about brain function based on behavioral data are somewhat precarious (Flanagan, 1984). Of particular concern is that much of the ontogenetic analysis of brain function is susceptible to the logical fallacy that absence of evidence constitutes evidence of absence.

A specific example pertinent to the present experimental findings concerns latent inhibition (LI). This behavioral phenomenon involves the tendency of animals to express weaker learned reactions to familiar as opposed to novel stimuli (Lubow, 1989). Lesion studies of adult rats have indicated that the hippocampus seems to be involved in LI (Salafia \& Allan, 1980; Solomon \& Moore, 1975). In several ontogenetic studies, researchers have failed to discover $\mathrm{LI}$ in rat pups younger than 20 days of age (Brennan \& Barone, 1976; Kraemer, Hoffmann, \& Spear, 1988; Nicolle, Barry, Veronesi, \& Stanton, 1989; Wil-

This research was supported in part by Grant BRSG RRO7114-21 awarded to P. J. Kraemer by the National Institutes of Health. The authors wish to thank K. Stone and J. Gettys for their assistance in completing this project. Correspondence should be addressed to Philipp J. Kraemer, Department of Psychology, University of Kentucky, Lexington, KY 40506. son, Phinney, \& Brennan, 1974). Given evidence that hippocampal lesions can disrupt $\mathrm{LI}$ in adults, the absence of $\mathrm{LI}$ in preweanling rats suggests that the ontogenetic emergence of LI may be correlated with the functional development of the hippocampus, which matures around Postnatal Day 19 (Nadel \& Zola-Morgan, 1984).

It may indeed be that hippocampal functioning is involved in the age-related expression of $\mathrm{LI}$, but it is also clear that the behavioral evidence is equivocal. Studies of aversive conditioning have shown that conditioned reactions to odors and tastes can be reduced by nonreinforced preexposure to these stimuli (Franchina, Domato, Patsiokas, \& Griesemer, 1980; Hoffmann \& Spear, 1989; Rudy \& Cheatle, 1979). Perhaps LI with olfactory and gustatory stimuli involves a different mechanism from that involved in other forms of learning, in which $L I$ has failed to appear in preweanlings, or perhaps differences in experimental parameters are crucial in determining whether or not LI will appear in immature rats.

Given these possibilities and the status of the evidence, we concur with the conclusion that " it is therefore best to view latent inhibition in relative rather than absolute terms"' (Nicolle et al., 1989, p. 355). Accordingly, even though LI in some situations may appear at an early age in rats, it may generally increase with age as relevant brain structures responsible for its appearance gradually mature. What is important, however, is that additional evidence of LI in immature rats be communicated, so that a more comprehensive empirical understanding of the developmental pattern of $\mathrm{LI}$ will emerge. It is in that sense that the following results are relevant. We report two experiments in which, using a CER procedure, we discovered evidence of $\mathrm{LI}$ in preweanling rats.

\section{METHOD}

\section{Subjects}

The subjects were Sprague-Dawley-derived rats born and reared in our colony at the University of Kentucky. Litters were culled to a maximum of 12 pups the day after birth. Litter mates were group housed with their dams throughout experimental testing. The animals were housed in plastic maternity cages fitted with stainless steel wire lids, which contained a water bottle and standard rat chow. 
The floor of the maternity cage was covered with pine shavings. All animals were housed in a climate-controlled vivarium that operated on a 16:8-h light:dark cycle; all experimental procedures occurred during the light portion of the cycle. In Experiment 1, separate groups of subjects were conditioned at 17 and 21 days of age, whereas in Experiment 2, all subjects were conditioned at 18 days of age.

\section{Apparatus}

The test box was housed in an animal isolation chamber, with the inside dimensions measuring $64 \mathrm{~cm}$ (length) $\times 48 \mathrm{~cm}$ (width) $\times 64 \mathrm{~cm}$ (height). The chamber was equipped with a side-mounted fan that provided both ventilation and constant background noise. A 7.5-W lamp was attached to the ceiling of the chamber. A 2.1-W lamp that provided constant dim illumination throughout the chamber was placed on the floor, along the wall that contained the fan. A speaker was placed on the floor of the test chamber, $10 \mathrm{~cm}$ away from the grid floor, and was used to present a 72-dB tone CS.

An ultrasonic activity monitor, modeled after that described by Moye and Rudy (1985), was mounted on the front wall of the isolation chamber, opposite the wall containing the fan. The device consists of a circular transmitter and receiver, each $2.4 \mathrm{~cm}$ in diameter, which were mounted $10 \mathrm{~cm}$ above the chamber floor and spaced $5 \mathrm{~cm}$ apart. Air-current disturbances, resulting from an animal's movement within the chamber, were detected as frequency discrepancies by the receiver and initiated closure of an electromechanical relay. Each relay closure constituted one activity count. The degree of movement of an animal within the chamber is positively correlated with the number of activity counts per unit of time. The sensitivity of the device was tuned by the procedure described by Moye and Rudy.

The chamber floor consisted of a 36-cm Plexiglas frame with stainless steel rods each $0.3 \mathrm{~cm}$ in diameter and spaced $0.5 \mathrm{~cm}$ apart. This grid floor was placed on the floor of the isolation chamber, centered under the ceiling-mounted light. The grid floor was attached to a Lafayette Instruments scrambled shock generator (Model 82404-SS). Fresh pine shavings were placed underneath the grid floor.

A flat gray, floor-less Plexiglas box, measuring $36 \mathrm{~cm}$ (length) $\times 25 \mathrm{~cm}$ (width) $\times 25 \mathrm{~cm}$ (height), was placed directly on the grid floor. It was equipped with two holes in the front wall, which allowed the transmitter and receiver of the activity monitor to extend slightly inside the box. The box was covered by a transparent Plexiglas lid. A three-chamber gray Plexiglas partition was placed inside the box during the conditioning phase of the experiment. This unit divided the test box into three chambers of equal size, each measuring $24 \mathrm{~cm}$ (length) $\times 11 \mathrm{~cm}$ (width) $\times 25 \mathrm{~cm}$ (height). All stimulus events and response recording were controlled by a Commodore 64 computer and a Lafayette Instruments interface (Model 1195-02), both attached to appropriate electromechanical relay equipment.

\section{Procedure}

The same general procedure was followed in both experiments, with some differences between experiments in training and test parameters. The target learning episode involved exposing subjects to a $15-\mathrm{sec}$ CS, which terminated with a .75-sec, 1-mA scrambled footshock. The subjects in Experiment 1 were trained with 18 CS-US (conditioned-stimulus-unconditioned-stimulus) pairings, and the subjects in Experiment 2 were trained with 12 CS-US pairings. Some subjects were also given nonreinforced exposure to stimuli $1 \mathrm{~h}$ before the conditioning episode. The preexposed stimuli were presented for a 15 -sec duration. The preexposed subjects received $24 \mathrm{CS}$-alone presentations in Experiment 1 and $20 \mathrm{CS}$-alone presentations in Experiment 2. All stimulus presentations during preexposure and conditioning were separated by a variable-time 90 -sec schedule.

All subjects were trained with a light-tone compound, which provides a more salient $\mathrm{CS}$ and produces stronger conditioning than does an element CS. One group in each experiment was given nonreinforced exposure to the compound $\mathrm{CS}$ prior to conditioning (Group LT-LT), and the other group had no prior experience with the CS before conditioning (Group LT). The nonpreexposed subjects in Experiment 1 were not handled during the preexposure phase, but the nonpreexposed subjects in Experiment 2 were exposed to the training context for the same duration as that for the preexposure group.

The test procedure involved exposing subjects individually to the test chamber and measuring activity counts in the presence and absence of a test stimulus. Conditioned fear is evident with this procedure as a decrement in general activity during presentation of a fear-evoking stimulus, relative to activity in the absence of that stimulus (Kraemer \& Spear, 1990; Moye \& Rudy, 1985). A slightly different test procedure was used in each experiment. In Experiment 1 , the subjects were tested for a 6-min period, divided into six 1-min intervals. The test stimulus was presented throughout Intervals 3 and 6, and it was not presented during Intervals $1,2,4$, and 5 . Cumulative activity counts were recorded for each of the six intervals separately.

A slightly different test procedure was implemented in Experiment 2 . If more than 19 activity counts were recorded during a 30 sec pre-CS interval, the CS was then presented during the next 30 sec interval. If the number of activity counts failed to meet this criterion, another 30-sec pre-CS interval occurred, and this continued until the criterion baseline level of activity was achieved. After presentation of the CS, the test sequence was repeated a second time, and a cumulative suppression ratio was calculated for each subject according to the following: activity counts during the two pre-CS intervals / sum of the activity counts during the two pre-CS intervals and two CS intervals. The value of this test procedure is that it permits one to avoid problems associated with extremely low baseline levels of activity, and it makes it more likely that baseline levels of activity will be equated across groups, both of which can increase the validity of the suppression ratio measure (LoLordo, 1979).

\section{RESULTS}

\section{Experiment 1}

Mean activity counts over the six test intervals and mean cumulative suppression ratios for preexposed and nonpreexposed subjects at each of the two ages tested appear in Table 1. In order to compare relative levels of conditioned fear expressed by the two groups, suppression ratios were calculated as follows: total activity counts during Test Intervals 3 and $6 /$ total activity counts during Test Intervals 2, 3, 5, and 6. Although suppression ratios of this nature can be used to compare levels of learned fear across groups that express different baseline levels of activity, group comparisons under these conditions are more difficult to interpret (LoLordo, 1979). Thus, we first

Table 1

Dependent Measures for Experiment 1

\begin{tabular}{llccccccc}
\hline & & \multicolumn{7}{c}{ Test Interval } \\
\cline { 3 - 8 } Age & Group & 1 & 2 & 3 & 4 & 5 & 6 & SR \\
\hline 17 & LT & 111.5 & 88.8 & 17.8 & 57.9 & 91.7 & 23.7 & 0.16 \\
17 & LT-LT & 118.7 & 97.9 & 31.7 & 74.3 & 94.7 & 48.2 & 0.27 \\
21 & LT & 106.8 & 72.9 & 20.0 & 48.8 & 65.2 & 19.8 & 0.19 \\
21 & LT-LT & 112.2 & 86.8 & 47.8 & 59.8 & 83.7 & 34.5 & 0.33 \\
\hline
\end{tabular}

Note-Mean activity counts during each of six test intervals are presented for both 17- and 21-day-olds in non-CS-preexposed (Group LT) and CS-preexposed (Group LT-LT) conditions. CS presentations occurred during Intervals 3 and 6 . SR refers to suppression ratio. 
Table 2

Dependent Measures for Experiment 2

\begin{tabular}{lccccc}
\hline Group & Test & Pretest Int & Pre-CS AC & CS AC & SR \\
\hline LT & 1 & 1.3 & 37.6 & 5.4 & 0.11 \\
LT & 2 & 4.6 & 33.9 & 6.1 & 0.11 \\
& & & & Cumulative & 0.14 \\
LT-LT & 1 & 2.1 & 41.0 & 17.4 & 0.27 \\
LT-LT & 2 & 3.5 & 34.0 & 9.0 & 0.18 \\
& & & & Cumulative & 0.24 \\
\hline
\end{tabular}

Note-Pretest Int, mean number of pre-CS intervals that preceded the CS interval; Pre-CS AC and CS AC, mean number of activity counts during pre-CS baseline test interval and CS interval, respectively; SR, suppression ratio. Separate suppression ratios are indicated for Tests 1 and 2 , as well as the cumulative suppression ratio for both tests combined.

analyzed baseline activity levels, which correspond to Test Intervals 2 and 5 . There were no significant differences in activity counts between Group LT and Group LT-LT during Test Interval 2 or 5 at either age. Suppression ratios, however, were significantly higher in Group LT-LT than in Group LT among 17-day-olds $[t(22)=2.26, p<$ $.04]$ and among 21-day-olds $[t(22)=2.17, p<.05]$.

\section{Experiment 2}

The mean number of pre-CS intervals, the mean activity counts during the CS intervals for each of the two test sequences, and the mean cumulative suppression ratios for each of the two groups appear in Table 2. No statistically significant differences between the two groups were found in either the number of pre-CS intervals required before presentation of the test stimulus or the number of activity counts during either of the two pre-CS baseline intervals. Thus, once again, analysis of suppression ratios was justified, and this analysis indicated that suppression ratios for Group LT-LT were significantly higher than those for Group LT $[t(21)=3.42, p<.01]$.

\section{DISCUSSION}

The results of both experiments indicate that the level of fear expressed to a light-tone CS was attenuated by nonreinforced preexposure to that stimulus. We found that 17-, 18-, and 21-day-old rat pups showed a CS preexposure effect like that found in adults tested in a similar situation with comparable parameters (Kraemer, Randall, \& Carbary, 1991). We interpret these results as evidence of latent inhibition in preweanling rats.

One caveat to our conclusion is that there are claims that the parameters used in these experiments invoke a phenomenon other than latent inhibition-that is, the transient preexposure effect (Best \& Gemberling, 1977). We believe, however, that there is neither sufficient empirical evidence nor an adequately articulated theoretical structure at this time to justify a functional distinction between CS-preexposure effects observed with different parameters. The possibility that a CS-preexposure experience may be forgotten, a proposition that has strong empirical support (e.g. , Kraemer et al., 1991; Kraemer \& Roberts, 1984), seems sufficient to capture the kinds of differences that have lead to a distinction between kinds of CS preexposure (see Best, 1982). Until such a process distinction is adequately established, it seems imprudent to characterize particular parametric variations of the CSpreexposure effect as being something other than LI (cf. Nicolle et al., 1989). Nonetheless, even if such a process distinction does become empirically sanctioned, the current findings remain relevant because they demonstrate that at least some forms of CS preexposure affect the behavior of the immature rat in the same way as that in which adults are affected.

The important implication of these results is that whatever neurological mechanism is necessary for the expression of LI, that mechanism is operating in preweanling rats. This conclusion does not imply that the neurological substrate for LI functions as well in preweanlings as it does in adults, nor that LI will be evident in immature rats with all kinds of learning procedures (see Kraemer et al., 1988; Nicolle et al., 1989). Rather, we suggest that we have discovered additional empirical evidence of a CSpreexposure effect in the immature rat, and that this and other evidence of $\mathrm{LI}$ in preweanling rats (e.g., Franchina et al., 1980; Hoffmann \& Spear, 1989; Kraemer et al., 1988; Rudy \& Cheatle, 1979) is important both for the analysis of behavioral development and for understanding the biological basis of learning and memory (see, e.g., Nadel \& Zola-Morgan, 1984; Nicolle et al., 1989; Sutherland \& Rudy, 1989).

\section{REFERENCES}

AMSEL, A. (1986). Developmental psychobiology and behavior theory: Reciprocating influences. Canadian Joumal of Psychology, 40, 311-342.

Bachevalier, J., \& Mishinin, M. (1984). An early and late developing system for learning and retention in monkeys. Behavioral Neuroscience, 98, 770-778.

Best, M. R. (1982). Nonassociative and associative sources of interference with the acquisition of a flavor aversion. In $M$. L. Commons, R. J. Herrnstein, \& A. R. Wagner (Eds.), Quantitative analyses of behavior (Vol. 3, pp. 67-85). Cambridge, MA: Ballinger.

Best, M. R., Gemberung, G. A. (1977). Role of short-term processes in the conditioned stimulus preexposure effect and the delay of reinforcement gradient in long-delay taste-aversion learning. Joumal of Experimental Psychology: Animal Behavior Processes, 3, 253-263.

Brennan, J. F., BArone, R. J. (1976). Effects of differential cue availability in an active avoidance CS for young and adult rats. Developmental Psychobiology, 9, 237-244.

Flanagan, O. J. (1984). The science of the mind. Cambridge, MA: Bradford.

Franchina, J. J., Domato, G. C., Patsiokas, A. T., * Griesemer, H. A. (1980). Effects of preexposures on sucrose taste aversion in weanling rats. Developmental Psychobiology, 13, 25-31.

HoffmANn, H., SPEAR, N. E. (1989). Facilitation and impairment of conditioning in the preweanling rat after prior exposure to the conditioned stimulus. Animal Learning \& Behavior, 17, 63-69.

Kols, B. M., * Whishaw, I. Q. (1990). Human neuropsychology. New York: W. H. Freeman.

Kraemer, P. J., Hoffmann, H., \& Spear, N. E. (1988). Attenuation of the CS-preexposure effect after a retention interval in preweanling rats. Animal Leaming \& Behavior, 16, 185-190.

Kraemer, P. J., Randall, C. K., Carbary, T. J. (1991). Release from latent inhibition with delayed testing. Animal Learming \& Behavior, 19, 139-145. 
Kraemer, P. J., \& Roberts, W. A. (1984). The influence of flavor preexposure and test interval on conditioned taste aversions in the rat. Learning \& Motivation, 15, 259-278.

Kraemer, P. J., Spear, N. E. (1990). Preweanling and adult rats treat conditioned light-tone combinations differently. Animal Learming \& Behavior, 18, 113.123.

LoLordo, V. M. (1979). Classical conditioning: The Pavlovian perspective. In M. E. Bitterman, V. M. LoLordo, J. B. Overmier, \& M. E. Rashotte (Eds.), Animal learning (pp. 25-60). New York: Plenum.

LUBOw, R. E. (1989). Latent inhibition and conditioned attention the ory. New York: Cambridge University Press.

Meck, W. H., ChURCh, R. M., Olton, D. S. (1984). Hippocampus, time, and memory. Behavioral Neuroscience, 98, 3-22.

Mishkin, M., Malamut, B., Bachevalier, J. (1984). Memories and habits: Two neural systems. In G. Lynch, J. L. McGaugh, \& N. M. Weinberger (Eds.), Neurobiology of memory (pp. 65-77). New York: Guilford.

MoYE, T. B., RUDY, J. W. (1985). Ontogenesis of leaming: VI. Leamed and unlearned responses to visual stimulation in the infant rat. Developmental Psychobiology, 18, 395-409.

NADEL, L., \& Zola-Morgan, S. (1984). Infantile amnesia: A neurobiological perspective. In $\mathrm{M}$. Moscovitch (Ed.), Infant memory (pp. 145-172). New York: Plenum.

Nicolle, M. M., Barry, C. C., Veronesi, B., Stanton, M. E.
(1989). Fornix transections disrupt the ontogeny of latent inhibition in the rat. Psychobiology, 17, 349-357.

Olton, D. S., Becker, J. T., \&andelmann, G. E. (1979). Hippocampus, space, and memory. Behavional \& Brain Sciences, 2, 313-365.

Rudy, J. W., \& Cheatle, M. D. (1979). Ontogeny of associative learning: Acquisition of odor aversions by neonatal rats. In N. E. Spear \& B. A. Campbell (Eds.), Ontogeny of learning and memory (pp. 157188). Hillsdale, NJ: Erlbaum.

Salafia, W. R., Allan, A. M. (1980). Conditioning and latent inhibition with electrical stimulation of hippocampus. Physiological Psychology, 8, 247-253.

Solomon, P. R. Moore, J. W. (1975). Latent inhibition and stimulus generalization of the classically conditioned nictitating membrane response in rabbits. Journal of Comparative \& Physiological Psychology, 89, 1192-1203.

Sutherland, R. J., Rudy, J. W. (1989). Configural association theory: The role of the hippocampal formation in learning, memory, and amnesia. Psychobiology, 17, 129-144.

Wilson, L. M., Phinney, R. L., \& Brennan, J. F. (1974). Age-related differences in avoidance behavior in rats following CS preexposure. Developmental Psychobiology, 7, 421-427.

(Manuscript received August 2, 1991; revision accepted for publication October 24, 1991.) 